\title{
A rare muscular variation: the third of the rhomboids
}

\author{
Lazar Jelev, Boycho Landzhov \\ Department of Anatomy, Histology and Embryology, Medical University of Sofia, Sofia, Bulgaria
}

\begin{abstract}
During superficial back dissection of a 72-year-old male cadaver, an interesting aberrant muscle was observed bilaterally below the lower border of the rhomboideus major. The unusual muscle arose by a thin aponeurosis from the spinous processes of the mid-thoracic vertebrae and was attached laterally to the lowest part of the medial border of the scapula. Because of its characteristics the authors proposed the term - the third rhomboid (m. rhomboideus tertius).
\end{abstract}

Key words: human; muscle variation; the third rhomboid

Anatomy 2012-2013;6-7:63-64, (C) 2012-2013 TSACA

\section{Introduction}

Because of their relatively superficial location, the rhomboid muscles (mm. rhomboidei) have been well investigated in humans. ${ }^{[1-5]}$ Their morphology seems to be quite constant $^{[5]}$ with a few exceptional variations reported. Beyond the common descriptions of variations in rhomboids' spinal origin, ${ }^{[1,2,4]}$ there are reports of rare additional slips and aberrant muscles related to the rhomboids. ${ }^{[5-7]}$ Knowledge of the precise scope of attachment as well as all possible additional muscles may help in improving the surgical uses of rhomboids. ${ }^{[8,9]}$

\section{Case Report}

During routine anatomical dissection of the superficial back structures of a 72-year-old Caucasian male cadaver, an interesting aberrant muscle (Figures 1a and b) was observed after removing the trapezius and latissimus dorsi layers. The unusual muscle was well developed bilaterally. It obviously belonged to the layer of levator scapulae and rhomboids and was located below the lower border of the rhomboideus major. The aberrant muscle started with a thin aponeurosis from the T6-T8 spinous processes on the left and T6-T7 spinous processes on the right side. The maximal width of the muscular part on the left was $40 \mathrm{~mm}$, compared to the $27 \mathrm{~mm}$ on the right side. On both sides the muscle fibers directed nearly horizontally to insert into the lowest part of the medial border of the scapula. Careful dissection of the left side muscle revealed an innervation by the dorsal scapular nerve (Figure 1c). The muscle probably acts in a similar way to the rhomboids but predominantly on the inferior angle of the scapula.

\section{Discussion}

In the anatomical literature there are descriptions of some rhomboid slips that miss their usual scapular attachments and merge with some of the neighboring muscles - teres major, latissimus dorsi, serratus anterior. ${ }^{[1,3,4]}$ Located over the rhomboideus minor, between it and the levator scapulae, there may be an additional muscle arising from either the occipital bone ("rhomboideus occipitalis") ${ }^{[1,4]}$ or the atlas ("atlanto-rhomboideus") ${ }^{[6]}$ and inserting to the superior part of the medial scapular border. Two aberrant muscular structures have been described below the lower border of the rhomboideus major. In a case of bilateral incomplete agenesis of the trapezius, von Haffner ${ }^{[7]}$ observed a small muscle, on the right side, stretched between the sixth thoracic vertebrae and the inferior angle of the scapula. He termed it as " $\mathrm{m}$. rhomboideus minimus" (the smallest rhomboid). A muscular slip called " $\mathrm{m}$. rhomboideus minus" (smaller rhomboid) has been described in $11-14 \%$ of the Japanese ${ }^{[5]}$ It arises from the spinous process above the latissimus dorsi origin, runs laterally and gradually disappears or passes into the fascia of the teres major. In our case, however, the reported aberrant muscle, despite having a similar location, is not small- 

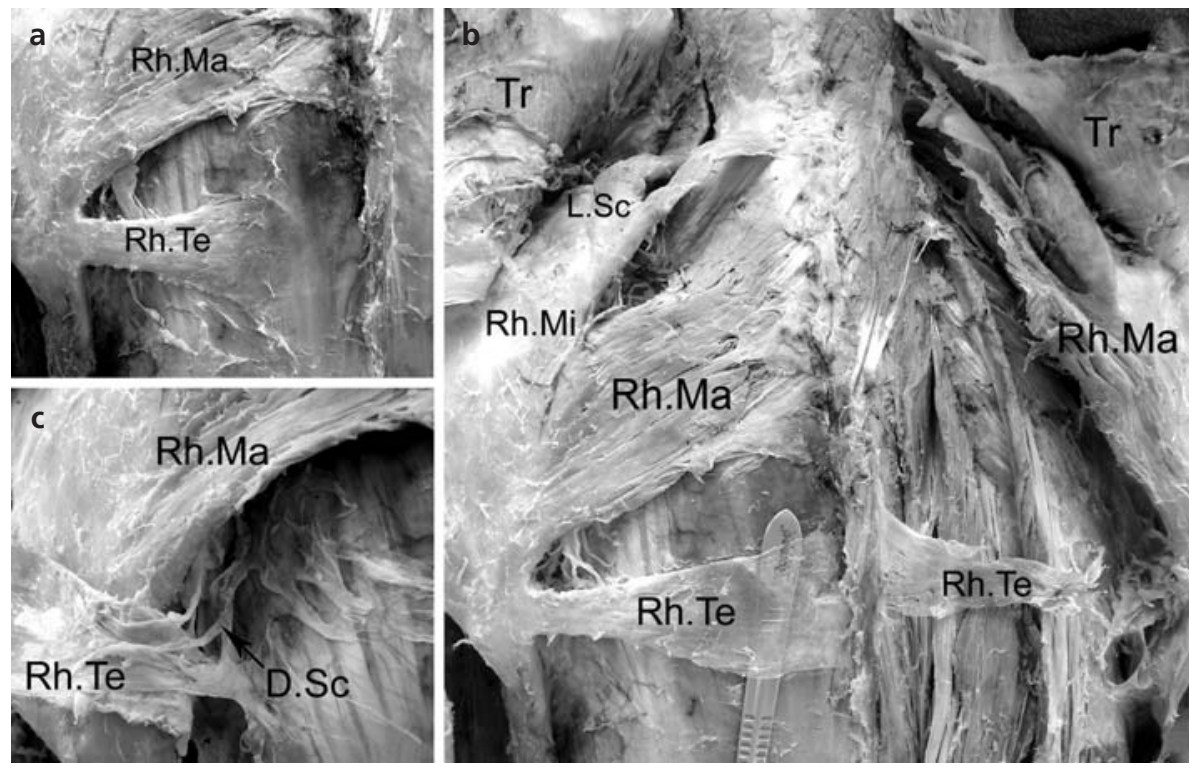

Figure 1. Photograph of the superficial back structures after removal of the trapezius and latissimus dorsi layers. The right aberrant muscle was accidentally damaged by student dissection. (a) the left side aberrant muscle before dissection. (b) the aberrant third rhomboids are shown on both sides with a scalpel handle inserted beneath the aponeurosis of the left variant muscle. (c) the terminal part of the dorsal scapular nerve is shown entering the left aberrant muscle. Muscles Rh.Ma: rhomboideus major; Rh.Mi: rhomboideus minor; Rh.Te: rhomboideus tertius; L.Sc: levator scapulae; Tr: trapezius. Nerve - D.Sc: dorsal scapular nerve.

er in size than the rhomboideus minor. So, a more plausible term for such a muscle would be "the third rhomboid" (m. rhomboideus tertius).

The existence of the described muscular variation could be explained with some unusual development of the rhomboid anlage. This happens in a relatively later stage of the process of muscle formation. ${ }^{[10]}$ In a $14 \mathrm{~mm}$ embryo the rhomboid mass can be seen covering only the uppermost portion of the serratus posterior superior as a part of the common muscular mass located between the dorsal border of the scapula and the spinous processes. In later stages, the rhomboids gradually migrate caudally, ${ }^{[10]}$ together with the whole shoulder girdle, to reach their usual location. Probably, during the process of migration the lowest part of the rhomboid anlage may separate and give rise to the third, well-defined rhomboid muscle.

From the literature review it seems that the reported aberrant rhomboid is a rare occasion. When found during surgery, however, it can be used together with the usual rhomboids for intrathoracic muscle flap transfer ${ }^{[8]}$ or muscle transfer for paralysis of the trapezius. ${ }^{[9]}$

\section{Acknowledgments}

The authors thank Ms. Elena Edward Fadel for English proof-reading of the text.

\section{References}

1. Bryce TH. Myology. In: Shafer ES, Symington J, Bryce TH, eds. Quain's Anatomy. Vol. VI, Part II, 11th ed. New York: Longmans, Green and Co.; 1923. p. 94-6.

2. Clemente CD (ed.) Anatomy of the Human Body. 30th ed. Philadelphia: Lea and Febiger; 1985. p. 515-6.

3. Le Double A-F. Muscles de la nique et du dos. In: Traité des variations du système musculaire de l'homme. Tome I. Paris: Schleicher Frères; 1897. p. 191-242.

4. Macalister A. Additional observations on muscular anomalies in human anatomy (third series), with a catalogue of the principal muscular variations hitherto published. Trans Roy Irish Acad 1875;25:1130.

5. Mori M. Statistics on the musculature of the Japanese. Okajimas Fol Anat Jap 1964;40:195-300.

6. Ruge G. Anleitungen zu den Präparierübungen an der menschlichen Leiche. I Bd, 4. Aufl. Leipzig: Verlag von Wilhelm Engelmann; 1908. p. 202-6.

7. von Haffner H. Eine seltene doppelseitige Anomalie des Trapezius. Internationale Monatsschrift für Anatomie und Physiologie 1903;20: 313-8.

8. Grima R, Krassas A, Bagan P, et al. Treatment of complicated pulmonary aspergillomas with cavernostomy and muscle flap: interest of concomitant limited thoracoplasty. Eur J Cardiothorac Surg 2009; 36:910-3.

9. Romero J, Gerber C. Levator scapulae and rhomboid transfer for paralysis of trapezius. J Bone Joint Surg Br 2003;85:1141-5.

10. Lewis WH. The development of the muscular system. In: Keibel F, Mall FP (eds.) Manual of Human Embryology. Vol. 1. J.B. Philadelphia and London: Lippincott; 1910. p. 454-522.

Correspondence to: Lazar Jelev, MD, PhD

Department of Anatomy, Histology and Embryology, Medical University of Sofia blvd. Sv. Georgi Sofiisky 1, BG-1431, Sofia, Bulgaria

Phone: +359-2-91-72-636 Fax: +359-2-851-87-83

e-mail: ljelev@abv.bg

Conflict of interest statement: No conflicts declared. 